This plus the immediacy of the reaction suggest that his death was unlikely to have been due to toxicity.

Nebulised lignocaine may cause narrowing of the airways in patients with asthma, ${ }^{2}$ but this is rarely of clinical importance especially as nebulised bronchodilators are given before fibreoptic bronchoscopy. Hypersensitivity to lignocaine is uncommon. Urticarial reactions may occur, ${ }^{3}$ and deaths due to anaphylaxis after small doses of injected local anaesthetic have been reported. ${ }^{45}$ We believe that this is the first reported death due to topical lignocaine during fibreoptic bronchoscopy. This procedure, however, remains safe with few complications.

1 Credle W, Smidy J, Elliott RC. Complications of fibreoptic bronchoscopy. Am Rev Respir Dis 1974;109:67-72.

2 Weiss EB, Patwardhan AV. The response to lidocaine in bronchial asthma. Chest 1977;72:429-38. 3 Waldman HB, Binkley C. Lignocaine hypersensitivity: report of a case. $f$ Am Dent Assoc 1967;74:747-9.

4 Morisset LM. Fatal anaphylactic reaction to lidocaine. Amed Forces Medical fournal 1957;8:740-4.

5 Kirkler DM. Allergy to lignocaine. Lancet 1962;i:159.

(Accepted 11 March 1987)

Department of Respiratory Medicine, East Birmingham Hospital, Birmingham B9 5ST

S P RUFFLES, MRCP, MRCGP, registrar

J G AYRES, MD, MRCP, consultant physician

Correspondence to: Dr Ruffles.

\section{Minimising bruising in the antecubital fossa after venepuncture}

Because of the large number of bruises seen after venepuncture of the antecubital fossa in patients presenting for anaesthesia we investigated the phenomenon.

\section{Methods and results}

We recruited 20 volunteers (eight men and 12 women) aged $20-47$ with blood pressures of less than $150 / 95 \mathrm{~mm} \mathrm{Hg}$. Each had $5 \mathrm{ml}$ of blood taken from both antecubital fossas by means of a green, 21 gauge Monoject needle and a tourniquet inflated to exactly half the diastolic blood pressure to promote venous congestion. After deflation of the tourniquet haemostasis was promoted by one of two methods based on our observations of current ward practice. In the first method the subjects pressed the contralateral thumb on to a cotton wool ball ove the site of venepuncture, keeping the elbow extended. In the second method the subject flexed the elbow, keeping the cotton wool ball over the puncture site. Both methods were used for two minutes, and the site was then inspected for 15 seconds. If bleeding had not stopped the method was repeated for one minute with the same inspection procedure; this was repeated until there was no visible bleeding. An adhesive dressing was then applied.

Subjects were randomised for which arm was to be flexed or extended and thus served as their own controls. All venepunctures were performed by the same investigator. A criterion of the study was that subjects with "difficult veins" and more than one clean puncture of the vein were excluded, as were those who had recently taken aspirin; in practice there were no exclusions. After 48 hours a second investigator, who was unaware of which method of haemostasis had been used, examined the venepuncture sites. Any visible bruising was noted and the area measured with tracing paper and a planimeter; the subject was asked about any symptoms associated with the bruising.

Flexing of the elbow after venepuncture produced visible bruising in 15 subjects compared with only six when the arm was held straight $(p<0.05$ by McNemar's test for paired data). In addition, the area of bruising was greater in the elbows that were flexed (median $0.55 \mathrm{~cm}^{2}$ and maximum $4.88 \mathrm{~cm}^{2}$ compared

Bruising 48 hours after venepuncture using two different methods to promote haemostasis

\begin{tabular}{lccc}
\hline & Total & $\begin{array}{c}\text { No } \\
\text { bruised }\end{array}$ & $\begin{array}{c}\text { Median (range) } \\
\text { area of bruise }\left(\mathrm{cm}^{2}\right)\end{array}$ \\
\hline $\begin{array}{l}\text { Elbow flexed: } \\
\text { Left arm }\end{array}$ & 10 & 8 & $0 \cdot 56(0-3 \cdot 62)$ \\
$\begin{array}{l}\text { Right arm } \\
\text { Elbow straight: }\end{array}$ & 10 & 7 & $0 \cdot 39(0-4 \cdot 88)$ \\
Left arm & 10 & 3 & $0(0-4 \cdot 84)$ \\
Right arm & 10 & 3 & $0(0-1 \cdot 84)$ \\
\hline
\end{tabular}

with median $0 \mathrm{~cm}^{2}$ and maximum $4.84 \mathrm{~cm}^{2}$ in the elbows that were extended; $\mathrm{p}<0.01$ by Wilcoxon's test for paired differences).

Thirty sites showed no visible bleeding after two minutes. One venepuncture site bled for over five minutes, but all the rest had stopped bleeding by 3 minutes 15 seconds. The time for bleeding to stop was unrelated to the size of the subsequent bruise $(p=0 \cdot 1$, Spearman's rank correlation coefficient).

\section{Comment}

We conclude that the common practice of flexing the elbow after venepuncture is not an efficient way of preventing bruising in the antecubital fossa.

We thank Professor W Mapleson for his kind help.

(Accepted 26 March 1987)

Department of Anaesthetics, University Hospital of Wales, Cardiff CF4 4XW A DYSON, MB, FFARCs, registrar in anaesthetics D BOGOD, MB, FFARCS, senior registrar in anaesthetics

Correspondence to: Dr Bogod.

\section{Huntington's disease: deterioration in clinical state during treatment with angiotensin converting enzyme inhibitor}

We report on a woman with Huntington's disease whose condition deteriorated dramatically during treatment with the angiotensin converting enzyme inhibitor captopril and improved on withdrawal of the drug.

\section{Case report}

A 47 year old woman who had been diagnosed eight years earlier as suffering from Huntington's disease was admitted to hospital for control of newly diagnosed hypertension $(210 / 120 \mathrm{~mm} \mathrm{Hg})$. She had previously been managed at home with haloperidol $1.5 \mathrm{mg}$ thrice daily. On examination she walked without help and had typical features of Huntington's disease, with diffuse involuntary choreiform movements, facial apraxia, and inability to protrude her tongue for longer than five seconds. Her higher mental functions were impaired, although she could communicate and follow simple commands. She was otherwise medically well and had no clinical features of end organ damage due to hypertension.

Haloperidol was continued and captopril $18.75 \mathrm{mg}$ daily in divided doses started. Because her blood pressure was unresponsive the dose was increased and over five days she received a total of $468.75 \mathrm{mg}$. Her clinical state then deteriorated and she became bedbound and totally unable to communicate and showed generalised rigidity and incontinence. She did not recognise her family and required nasogastric feeding. At no stage had she had any hypotensive episode, metabolic derangement, or fever. Her blood pressure remained raised throughout, with systolic pressure varying between 220 and $180 \mathrm{~mm} \mathrm{Hg}$ and diastolic pressure varying between 150 and $120 \mathrm{~mm} \mathrm{Hg}$. Extensive investigations including lumbar puncture, thyroid function tests, and computed tomography of the brain showed no cause for her altered neurological state. Captopril was stopped and her blood pressure eventually controlled with a combination of nifedipine, atenolol, and a thiazide diuretic. Her neurological state gradually improved, and five days after the captopril was stopped she had recovered her previous functional state. Her blood pressure was controlled, and she was discharged home.

\section{Comment}

Altered amounts of various neurotransmitters have been shown in the striatonigral system of patients with Huntington's disease, ${ }^{1}$ although the underlying biochemical defect that causes the disease is unknown. In a necropsy study Arregui et al showed that the corpus striatum and substantia nigra of patients with Huntington's disease had diminished quantities of angiotensin converting enzyme. ${ }^{2}$ This enzyme has been localised to the striatonigral pathway of rat brains in autoradiographic experiments with tritiated captopril. ${ }^{3}$

This patient's pronounced deterioration during treatment with captopril for hypertension and her subsequent recovery after withdrawal of the drug suggest that inhibition of angiotensin converting enzyme was the cause of her altered neurological state. This observation may have important 